\title{
HBV-HCV Coinfection: Viral Interactions, Management, and Viral Reactivation
}

\author{
Marianna G. Mavilia* and George Y. Wu \\ Department of Medicine, Division of Gastroenterology-Hepatology, University of Connecticut Health Center, Farmington, CT, USA
}

\begin{abstract}
Hepatitis B virus (HBV) and hepatitis C virus (HCV) coinfection is a complex clinical entity that has an estimated worldwide prevalence of $1-15 \%$. Most clinical studies have shown that progression of disease is faster in HBV-HCV coinfected patients compared to those with monoinfection. Hepatocellular carcinoma development appears to have higher rate in coinfections. Viral replication in coinfected cells is characterized by a dominance of HCV over HBV replication. There are no established guidelines for treatment of HBV-HCV coinfection. Studies on interferon-based therapies and direct-acting antivirals have shown varying levels of efficacy. Clinical reports have indicated that treatment of HCV without suppression of $\mathrm{HBV}$ increases the risk for $\mathrm{HBV}$ reactivation. In this review, we appraise studies on both direct-acting antivirals and interferon-based therapies to evaluate the efficacy and rates of reactivation with each regimen. Screening for and prevention of coinfection are important to prevent serious HBV reactivations.
\end{abstract}

Citation of this article: Mavilia MG, Wu GY. HBV-HCV coinfection: viral interactions, management, and viral reactivation. J Clin Transl Hepatol 2018;6(3):296-305. doi: 10.14218/JCTH.2018.00016.

\section{Introduction}

Hepatitis B virus (HBV) and hepatitis C virus (HCV) infections are among the leading causes of chronic liver disease worldwide. According to the World Health Organization, over 250 million people are currently infected with HBV and more than 70 million with $\mathrm{HCV}^{1}{ }^{1}$ While HBV and HCV share preference of replication in hepatocytes, their life cycles are completely different. HBV is a DNA virus that replicates in the nucleus, while HCV is an RNA virus that replicates exclusively in the cytoplasm of hepatocytes. However, they both have RNA replicative intermediates and theoretically can interact in coinfected cells, leading to varying viral expression and serologic patterns.

HBV-HCV coinfection is more complex than monoinfection with HBV or HCV alone. Coinfection is defined as the presence

Keywords: Hepatitis B virus; Hepatitis C virus; Coinfection; Viral reactivation. Abbreviations: DAAs, direct-acting antivirals; HBV, hepatitis B virus; HCC, hepatocellular carcinoma; HCV, hepatitis C virus; miRNA, micro RNA; PegIFN, pegylated-interferon.

Received: 1 March 2018; Revised: 25 April 2018; Accepted: 1 May 2018

*Correspondence to: Marianna G. Mavilia, Department of Medicine, University of Connecticut Health Center, 263 Farmington Ave, Farmington, CT 06032, USA. Tel: +1-860-679-2509, Fax: +1-860-679-6582, E-mail: mmavilia@uchc.edu of two or more replicating organisms in the same host. Coinfection with HBV and HCV can occur in two ways. Because $\mathrm{HBV}$ and HCV have some modes of transmission in common, namely intravenous drug use, blood transfusion and vertical transmission, viruses can be cotransmitted simultaneously. ${ }^{2}$ However, HCV-HBV coinfection may also occur by superinfection, meaning one virus is acquired in a patient with preexisting chronic infection by the other virus. Superinfection is the most common mechanism of developing coinfection, and HCV superinfection is seen more commonly than HBV superinfection. ${ }^{2-4}$

In clinical settings, one virus is typically dominant over the other. Dominance occurs when there is reciprocal inhibition of one viral genome by the other virus when both HBV and HCV are present in the same cell. ${ }^{5}$ The dominant virus replicates more actively and suppresses replication of the non-dominant virus. Codominance refers to near equal replication of both HBV and HCV.

Viral serologies vary depending on whether the coinfection is simultaneous or superinfection. HCV infection is almost always overt, meaning anti-HCV and HCV RNA can be detected in the serum. In contrast, HBV infection may be overt or occult. In occult HBV infection, hepatitis B surface antigen and HBV DNA are not present in serum but HBV DNA is detectable in the liver.

Coinfection can result in acute fulminant hepatitis, development of chronic hepatitis, or spontaneous clearance of one or both viruses. ${ }^{2,3}$ In the coinfected patient, viral interaction has implications for disease severity, clinical manifestations, and management. The aim of this review is to discuss the differences between monoinfection and coinfection with HBV and $\mathrm{HCV}$, and to review virus interactions and their impact on outcomes.

\section{Epidemiology}

The incidence of coinfection has been reported to range from $1-15 \%$ worldwide. ${ }^{3,6}$ However, this is likely to be an underestimation because of the possibility of unrecognized occult HBV infection. ${ }^{4}$ Incidence also varies significantly by geographic region, with higher rates of coinfection in areas endemic for each virus. ${ }^{5}$ The majority of available studies are from endemic areas. From a large study in the USA, a rate of coinfection of $1.4 \%$ has been reported. ${ }^{7}$ This low rate correlates with the low prevalence of HCV and HBV in the USA compared to high prevalence areas.

\section{Viral interaction}

Most in vitro studies have demonstrated that HBV and HCV coreplicate within the same hepatocytes without interference. ${ }^{5,8-11}$ 
Yang et al. ${ }^{10}$ developed a novel human hepatoma cell line that supports replication of both HBV and HCV. They were able to show near equal replication of HCV RNA and HBV DNA within coinfected cells, as measured by PCR. ${ }^{10}$ Furthermore, the magnitude of replication was the same in coinfected cells for each virus as for the respective monoinfected cells. They concluded that there is no direct interference between viral replication. ${ }^{10}$ This cell line was developed from a hepatoma removed from a male with chronic HCV infection. Although the cells were recultured in vitro and in mice prior to inoculation with both $\mathrm{HCV}$ and $\mathrm{HBV}$, it is unclear if the prior host $\mathrm{HCV}$ infection had any impact on the viral interaction in the coinfected cells.

Another study used the Huh-7 cell line to model viral interactions in coinfection. ${ }^{11}$ It was demonstrated that both viruses were able to replicate within the same hepatocyte using immunofluorescence analysis. Using an RNA polymerase inhibitor to stop HCV replication, no effect on HBV replication was observed. ${ }^{11}$ Similarly, induction of HBV replication in cells with tetracycline-controlled HBV failed to suppress $\mathrm{HCV}$ replication. ${ }^{11}$ It was concluded that the viral replication cycles were independent of each other in this model. ${ }^{11}$ Given the lack of viral interaction demonstrated by these in vitro studies, it has been postulated that any interactions seen clinically are more likely related to host immune responses. ${ }^{11}$ The latter study used modified viral preparations, which were selectively inducible to manipulate conditions. It is unclear if the viral responses observed as a result of this experimental method are applicable to spontaneously occurring HBV and $\mathrm{HCV}$.

Other in vitro studies have shown that the HCV core or nonstructural $5 \mathrm{~A}$ proteins may impact HBV replication. However, there are conflicting data, with evidence of both suppression and enhancement of HBV replication by HCV proteins. ${ }^{12-14}$ Eyre et al. ${ }^{13}$ examined the role of HCV core protein on HBV replication in coinfected Huh-7 cells. They demonstrated direct physical interaction of HCV core protein with HBV structural proteins through co-localization by confocal microscopy. ${ }^{13}$ Furthermore, they found that HBV replication was unchanged or slightly enhanced by the presence of HCV core protein as indicated by increased HBV DNA release in coinfected cells. ${ }^{13}$ These results were limited by the study's inclusion of only HCV genotype $2 \mathrm{a}$ and HBV genotype A.

Viral interaction between various combinations of genotypes may differ from the trends observed above. Pan et al. ${ }^{12}$ showed similar results with enhancement of HBV DNA production in the presence of $\mathrm{HCV}$ nonstructural $5 \mathrm{~A}$ protein. However, this study did not specify the viral genotypes used, and the host cell culture system was derived from a hepatocellular carcinoma (HCC) cell line. Conversely, a study by Schuttler et al. ${ }^{14}$ revealed a definitive 3 - to 11 -fold inhibition of the HBV enhancer regions by HCV core protein. This study examined multiple viral genotypes (accounting for the quantitative range in suppression) as well a multiple cell lines, making these results more convincing.

The in vitro results were not reproducible in animal models. One study demonstrated suppression of HBV replication in coinfected chimpanzees. ${ }^{9}$ This was found to be related to HCV-enhanced expression of alpha-beta interferon in liver cells, which played an inhibitory role on HBV replication. In this study, the chimpanzees were chronic HCV carriers superinfected with HBV. The authors attempted to apply the viral interaction observed here to all coinfected subjects without control studies on superinfection of HCV superinfection of chronic HBV carriers. Therefore, it is unclear if this interaction was related to the sequence of the infections.

Unlike in vitro data, clinical studies of human subjects have demonstrated viral interference in coinfected individuals. Most commonly, HBV replication is suppressed by $\mathrm{HCV}^{4,5}$ The exact mechanism of this interaction is not well understood, although several mechanisms have been proposed. In one theory, there is competition for the host hepatocyte machinery for replication. ${ }^{7}$ While this may play some role, it does not explain why HCV typically "wins" this competition. A number of studies have suggested that HBV suppression is mediated by HCV core protein. ${ }^{4,15-17}$ Normally, HBV replication begins with binding of HBV polymerase to the signal region of covalently closed circular DNA. ${ }^{18}$ In coinfection, the HCV core protein was found to complex with HBV polymerase and impede its function. ${ }^{15,18} \mathrm{An}$ in vitro study demonstrated that the phosphorylation of $\mathrm{HCV}$ core protein by protein kinases $\mathrm{A}$ and $\mathrm{C}$ enabled the suppressive activity. ${ }^{17}$

Influence from micro (mi)RNA represents another possible mechanism for the facilitation of HCV dominance. MiRNAs are short sequences of RNA that mediate cellular activities. MiRNA 122 is a liver-specific miRNA that has been shown to suppress HBV replication. ${ }^{18,19}$ Chen et al. ${ }^{18}$ demonstrated an inverse relationship between HBV replication and amount of miRNA 122. The authors theorized that miRNA 122 directly binds the target sequences of mRNA, preventing transcription. ${ }^{18}$ Many studies propose an immune-related regulation in coinfection. HCV infection activates interferon production within the hepatocytes. ${ }^{4}$ Interferon then exerts its antiviral effects on HBV. ${ }^{5}$ Fig. 1 depicts how these proposed mechanisms interrupt HBV replication.

\section{Serologic profiles}

There are four serologic profiles seen in coinfection: codominant, HCV dominant, HBV dominant, and neither replicative. The serologies for each are listed in Table 1 . The serologic profiles can evolve over time.

In HCV dominant coinfection, HCV actively replicates and suppresses HBV replication. A portion of HCV dominant cases may have occult HBV infection. As previously described, serum antibodies (anti-HBV surface protein and anti-HBV core protein) are typically positive in occult HBV infection. However, $20 \%$ of cases are negative for all serum markers. ${ }^{20}$ Due to this diagnostic limitation, occult HBV infection is often missed, but has been estimated to occur in up to $50 \%$ of high risk individuals with chronic $\mathrm{HCV}^{4,21}$

HBV dominant coinfection is less common, characterized by little to no HCV replication and active HBV replication. HBV is more likely to be the dominant virus following HBV superinfection. ${ }^{4}$ Rarely, neither virus is actively replicating characterized by positive serologies but negative PCR results. This state may change over time, transforming into active infections. A longitudinal study by Weigand et al. ${ }^{22}$ followed serologies of 85 coinfected patients over a 10 -year period. They found the frequency of each serologic pattern to be $18 \%$ codominant, $47 \%$ HCV dominant, $14 \%$ HBV dominant, and $21 \%$ neither replicative. ${ }^{22}$ This data clearly shows that HCV dominance is most common and is consistent with the trend toward HBV suppression as discussed above. However, the nonreplicative group seems to account for a significant fraction. This study may have been limited by a lack of control of antiviral therapy prior to enrollment. 


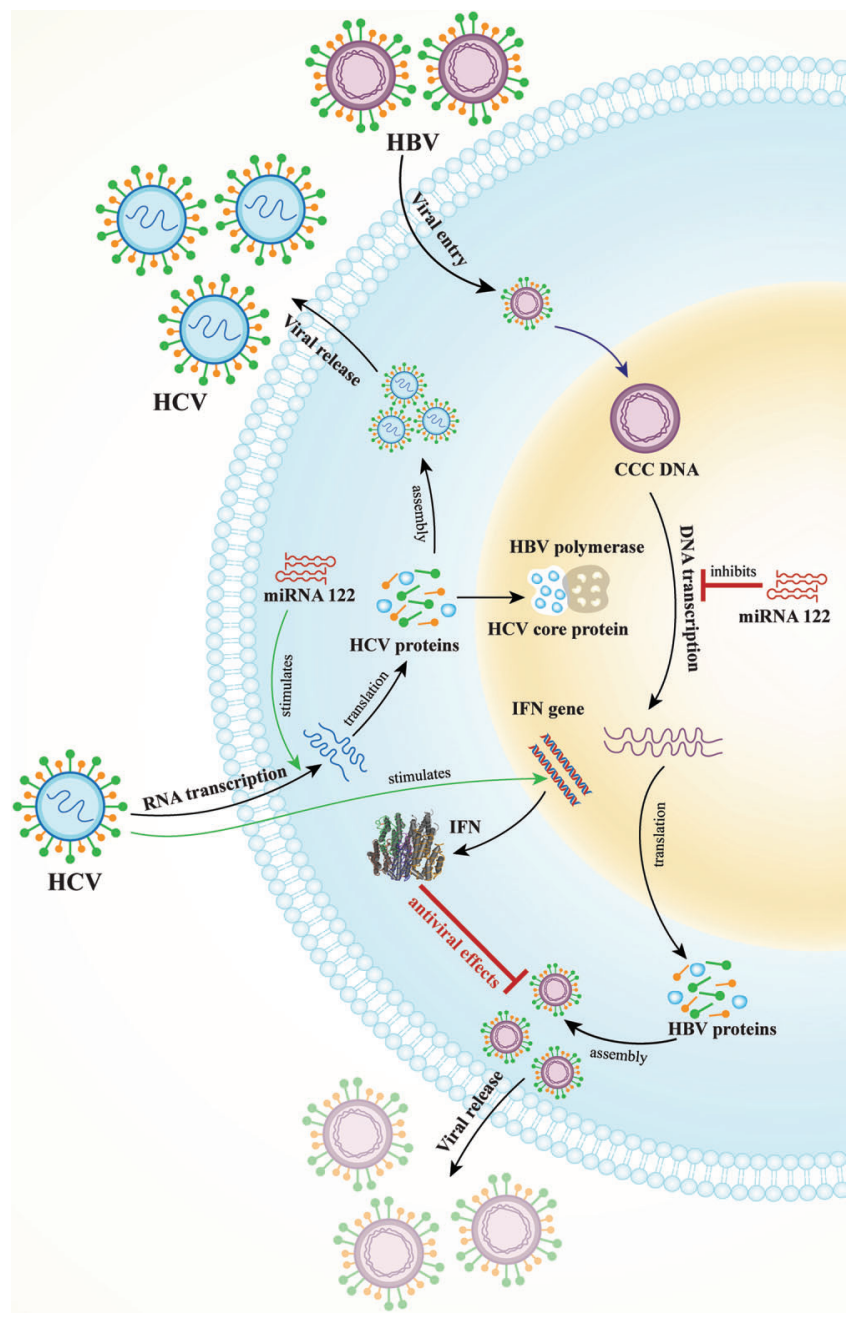

Fig. 1. A depiction of three proposed mechanisms of HCV suppression of HBV replication. First, HCV core protein complexes with HBV polymerase, deactivating it. Second, miRNA 122 inhibits HBV replication and stimulates HCV replication. Lastly, HCV stimulates the IFN gene to produce IFN, which exerts an antiviral effect on HBV. Abbreviations: HBV, hepatitis B virus; HCV, hepatitis C virus; IFN, interferon; miRNA, microRNA.

Another longitudinal study by Raimondo et al. ${ }^{23}$ found similar frequencies for each serologic pattern, with $23 \%$ codominant, $48 \%$ HCV dominant, 14\% HBV dominant, and $15 \%$ neither replicative. This study tracked the serologies every 2 months over a 1-year period, finding significant fluctuations in level of viremia and viral dominance pattern in $31 \%$ of cases. $^{23}$ The long-term variation, beyond 1 year, was not followed in this study. The authors did not discuss the clinical impact of these fluctuations. Unlike this study, Weigand et $a .^{22}$ in the study above, did not follow serologies over timed intervals. Therefore, the fluctuations over a long time course cannot be compared.

Although coinfection is characterized by the presence of viral nucleic acid of both viruses in serum, it has been shown that not all hepatocytes are infected by both viruses in coinfected individuals. Rodriguez-Inigo et al. ${ }^{24}$ evaluated liver biopsy specimens in six patients with chronic HCV and occult HBV infection. It was found that $12 \%$ of cells were infected with HBV only, $42 \%$ were infected with HCV only, and almost half, or $46 \%$, were coinfected with both viruses. ${ }^{24}$ While these results are interesting, the general applicability of the conclusions are limited by the small sample size, and the inclusion of coinfected individuals with only occult HBV infection.

\section{Coinfection versus monoinfection}

Coinfection may result in lower levels of viremia and circulating antigens of one or both viruses compared to monoinfection. An observational study comparing coinfection and monoinfection showed that HCV RNA levels were lower in coinfected patients than in HCV monoinfected patients, with average levels $415,000 \mathrm{IU} / \mathrm{mL}$ and $750,000 \mathrm{IU} / \mathrm{mL}$ respectively. ${ }^{8}$ Similarly, coinfected patients had decreased HBV DNA levels compared to their monoinfected counterparts $(143 \mathrm{IU} / \mathrm{mL}$ vs. $850,000 \mathrm{IU} / \mathrm{mL}){ }^{8}$ Another 10 -year longitudinal study observed that increased HCV RNA over time was correlated with decreasing levels of hepatitis B surface antigen. ${ }^{22}$

Additionally, increased rates of spontaneous viral clearance were seen in coinfection compared to monoinfection. Xiong et al. ${ }^{25}$ presented a large study of 1,918 patients followed over 6 months to evaluate for factors associated with $\mathrm{HCV}$ clearance. The pooled rate of clearance was $46.4 \%$ in coinfection and $14.4 \%$ in monoinfection. Of note, spontaneous clearance of HCV was associated with higher levels of HBV DNA. ${ }^{25}$ Although this was a large study, it enrolled only intravenous drug users and blood donors. These specific groups introduce some selection bias as well as possible issues with compliance and follow up. This was a longitudinal study, but only provided 6 months of follow up. In order to better assess clearance, a longer follow up period would have been useful.

Similar trends were seen in spontaneous clearance of HBV in coinfected patients. Sheen et al. ${ }^{5,26}$ conducted a 6 year follow up study showing the incidence of hepatitis B surface antigen clearance to be 2.5 times greater in coinfection. The seroclearance rate was $2 \%$ per year. ${ }^{16,26}$ This was a small study $(n=54)$. However, participants in the coinfected and monoinfected groups were well matched for multiple confounding factors.

\section{Effects of coinfection on severity of liver disease}

Higher rates of cirrhosis and increased severity of liver disease have been reported with coinfection compared to both HBV monoinfection and HCV monoinfection. $4,8,27,28$ Some studies estimated the risk of advanced liver disease to be increased 2 - to 3 -fold in coinfection, ${ }^{29}$ while others reported no difference in disease severity. ${ }^{4}$

Table 2 lists nine representative studies comparing liver disease severity in coinfection compared to monoinfection. ${ }^{3,8,20,28,30-33}$ Six out of the nine studies showed higher rates of advanced liver disease in the coinfected group. For instance, a multicenter prospective study done in France comparing exposure matched pairs with HBV and HCV monoinfection relative to coinfection found that severe fibrosis, measured by FibroScan, was more common in coinfection (58\% vs. $32 \%) .^{3}$ They also found that decompensated cirrhosis was more common in coinfection $(11 \%$ vs. $2-4 \%) .^{3}$ This was a well-designed, large study which controlled for concomitant HIV infection, but did not control for variables associated with development of cirrhosis, such as fatty liver, alcohol use, medications, etc. Yang et al. reported similar results in a longitudinal cohort study comparing coinfected patients to 
Mavilia M.G. et al: HBV-HCV coinfection

Table 1. Serologic patterns in coinfection

\begin{tabular}{|c|c|c|c|c|}
\hline \multirow[t]{2}{*}{ Codominant } & \multicolumn{2}{|c|}{ HCV dominant } & \multirow[t]{2}{*}{ HBV dominant } & \multirow[t]{2}{*}{ Neither replicative } \\
\hline & HCV/Occult HBV & HCV/Overt HBV & & \\
\hline++ HCV RNA & +++ HCV RNA & +++ HCV RNA & - HCV RNA & - HCV RNA \\
\hline++ HBV DNA & - HBV DNA & + HBV DNA & +++ HBV DNA & - HBV DNA \\
\hline + Anti-HCV Ab & + Anti-HCV Ab & + Anti-HCV Ab & + Anti-HCV Ab & + Anti-HCV Ab \\
\hline$\pm \mathrm{HBsAg}$ & - HBsAg & + HBsAg & $+\mathrm{HBsAg}$ & - HBsAg \\
\hline+ Anti-HBc & \pm Anti-HBc & + Anti-HBc & + Anti-HBc & + Anti-HBc \\
\hline + Anti-HBs & \pm Anti-HBs & + Anti-HBs & + Anti-HBs & + Anti-HBs \\
\hline
\end{tabular}

Abbreviations: Ab, antibody; HBC, hepatitis B core protein; HBs, hepatitis B surface protein; HBsAg, hepatitis B surface antigen; HBV, hepatitis B virus; HCV, hepatitis B virus.

HBV monoinfected patients only. This study recruited noncirrhotic patients and monitored them for the development of cirrhosis. They also used propensity matching to control for some of the variables that the previously mentioned study did not.

Two of the nine studies in Table 2 showed contrasting results. ${ }^{8,20}$ Marot et al. ${ }^{8}$ and Cardoso et al. ${ }^{20}$ showed some subtle differences, but there were no statistically significant differences in disease severity with coinfection. Marot et al. ${ }^{8}$ conducted a study of 23 coinfected patients with matched controls for both HBV and HCV monoinfection, and found a higher rate of fibrosis/cirrhosis in coinfected individuals (19\%) compared to HBV monoinfection (14\%), but a lower rate compared to HCV monoinfected patients (29\%). By defining coinfection as presence of hepatitis $B$ surface antigen and HCV RNA, the authors excluded occult HBV infection in this study. However, the study was underpowered to evaluate for risk of cirrhosis. Similarly, Cardoso et al. ${ }^{20}$ analyzed liver biopsy samples from coinfected and HCV monoinfected patients and found higher rates of inflammation in coinfection group but higher rates of fibrosis in the HCV monoinfected group. Unlike the prior study, this study did include occult HBV infection in the coinfection group. ${ }^{20}$
There are differences among studies in Table 2 with regard to the metric of liver disease severity, ranging from presence of cirrhosis, FibroScan score, histologic findings or presence of hepatic decompensation. They also varied in sample size and inclusion criteria. Despite these differences, there was a consistent trend toward more advanced disease in coinfection. Because most of these studies were observational, the data demonstrated an association between coinfection and more severe liver disease, not necessarily a causal relationship.

Although the consensus in the literature seems to point towards increased severity of liver disease in coinfected patients, a small 10-year longitudinal study showed no mortality difference for coinfection compared to HBV monoinfection. ${ }^{30}$ The mortality rate in that study was $39.6 \%$ in the HBV monoinfected group versus $31.6 \%$ in the coinfected group. ${ }^{30}$ That study also only included hemodialysis patients, who have a high overall mortality due to their renal and cardiovascular comorbidities and, therefore, may not be a representative sample.

In contrast, a large retrospective study by Liu et al. ${ }^{29} \mathrm{com}-$ pared outcomes of coinfection compared to HCV monoinfection after treatment with PegIFN/ribavirin. Higher all-cause

Table 2. Studies evaluating liver disease severity in coinfection versus monoinfection

\begin{tabular}{|c|c|c|c|c|}
\hline Study & Metric of worsening liver disease & Coinfection, \% & $\begin{array}{l}\text { HBV } \\
\text { monoinfection, \% }\end{array}$ & $\begin{array}{l}\mathrm{HCV} \\
\text { monoinfection, \% }\end{array}$ \\
\hline Lee et $a l .{ }^{30}, 2011$ & Development of cirrhosis & 26 & 21 & - \\
\hline \multirow[t]{2}{*}{ Pol et al. ${ }^{3}, 2017$} & Fibrosis measure by FibroScan F3-4 & 58 & 32 & 52 \\
\hline & Decompensated cirrhosis & 11 & 2 & 4 \\
\hline Yang et al. ${ }^{28}, 2016$ & Development of cirrhosis & 28 & 14 & - \\
\hline \multirow[t]{2}{*}{ Yan et al. ${ }^{27}, 2016$} & Cirrhosis & 39 & - & 18 \\
\hline & Hepatic decompensation & 32 & - & 12 \\
\hline Gaeta et al. ${ }^{31}, 2003$ & Cirrhosis & 29 & 18 & - \\
\hline \multirow[t]{2}{*}{ Squadrito et al. ${ }^{32}, 2013$} & Advanced cirrhosis & 33 & - & 14 \\
\hline & Liver-related morality & 32 & - & 11 \\
\hline Zarski et al. ${ }^{33}, 1998$ & Cirrhosis on liver biopsy & 44 & - & 9 \\
\hline \multirow[t]{3}{*}{ Cardoso et al. ${ }^{20}, 2013$} & Severe inflammation score & 5 & - & 0 \\
\hline & Moderate to severe fibrosis score & 19 & - & 24 \\
\hline & Cirrhosis on liver biopsy & 5 & - & 5 \\
\hline Marot et al. ${ }^{8}, 2017$ & Fibrosis or cirrhosis & 19 & 14 & 29 \\
\hline
\end{tabular}


mortality (hazard ratio of 1.44) and liver-related mortality (hazard ratio of 1.94) was seen in the coinfected group. ${ }^{29}$ This may reflect the increased severity of liver disease in coinfection or it may be related to increased complications of treatment in coinfection, as rates of HBV reactivation were not addressed in that manuscript. More comprehensive data is needed to identify a mortality difference in this population.

\section{Coinfection in the pediatric population}

While the aforementioned studies refer to coinfected adults, similar trends towards more severe liver disease exist in coinfected children. One study of chronic hepatitis in children ages 5-17, including 10 children with coinfection, demonstrated a greater degree of necroinflammation in the coinfected group. ${ }^{34}$ There was a more significant difference when compared to HCV monoinfected children versus HBV monoinfection. While this information is useful for understanding the natural history and progression of liver disease in coinfected children, it is difficult to interpret with regard to implications for treatment. The USA Federal Drug Administration recently approved use of direct-acting antivirals (DAAs) (specifically ledipasvir/sofosbuvir and sofosbuvir/ribavirin) for HCV in children aged 12-17, but these agents are not approved for use in younger children. ${ }^{35}$ The increased severity in coinfected children highlights a potential benefit for expansion of DAA use. However, given the current guidelines for treatment, children under 12 years of age should be studied separately from those ages 12-17 since the impact on treatment is different.

Similar to HCV treatments, approved agents for treatment of HBV are also more limited in children and vary by age. Pegylated-interferon (PegIFN) is approved for use over 12 months of age, lamivudine and entecavir is approved for ages 2 and older, and adefovir and tenofovir are used in children greater than 12 years. ${ }^{36}$ The above agents for both $\mathrm{HCV}$ and $\mathrm{HBV}$ can presumably be used to treat coinfection in children. However, there are no specific recommendations regarding treatment of coinfected children.

\section{Effects of coinfection on development of HCC}

Coinfection may be associated with increased incidence of HCC. However, like an association with liver disease severity, this is also a controversial topic. Table 3 lists seven representative studies, which addressed the frequency of HCC in coinfection and monoinfection. ${ }^{28,32,34-38}$ The majority showed a higher percentage of HCC development in coinfected individuals.

In an Italian study, the incidence of HCC was $6.4 \%$ per year in coinfected patients, $2.0 \%$ in HBV monoinfection, and $3.7 \%$ in HCV monoinfection. $4,5,38$ The 10 -year cumulative rate of HCC development was $45 \%, 16 \%$ and $28 \%$ respectively. ${ }^{4,5,38}$ This study used an adequate follow up period of 5 years as the average time to development of HCC in cirrhotics, which has been estimated to be about 3 years. ${ }^{42}$ They only included Child-Pugh class A cirrhotics. Given this restriction, the results may be less generalizable to higher grade cirrhosis. Bevegnu et al. ${ }^{41}$ showed a similar trend with HCC developing in $36 \%$ of coinfected individuals, $6 \%$ of HCV monoinfected and $11 \%$ of HBV monoinfectioned. Unlike the prior mentioned study, all Child-Pugh class cirrhotics were included. This study also stratified results for various risk factors, including alcohol use, to minimize confounders. Oh et al. ${ }^{37}$ had similar results in a study of greater than 6,000 Koreans, where the hazard ratio for developing HCC was 115 in coinfection, 17 in HBV monoinfection and 10.4 in HCV monoinfection. These three studies achieved similar results, despite their regional difference (Italy versus Korea) in viral endemicity and support a causal relationship between coinfection and risk of HCC.

The exact mechanism for which dual infection increases risk for HCC is unknown. However, it has been postulated that the increased severity of liver disease, specifically increased inflammation, increases the oncogenicity. There may also be some carcinogenic synergy between the two viruses. ${ }^{4}$

Kuper et al. ${ }^{43}$ reported data that do not support an additive effect of coinfection on development on HCC. Of note, this study is not listed in Table 3 as it only reported odds ratios without absolute percentages. They reported odds ratios of 46.2, 53.4, and 32.3 for dual infection, HBV alone, and HCV alone, respectively. ${ }^{43}$ This suggests that HBV may have more oncogenic effect compared to HCV alone, and coinfected patients are at higher risk that HCV monoinfected patients. This raises the possibility of a protective effect in dual infection, where the HCV suppression of HBV replication may decrease the risk of HCC development if HBV is the main driver of HCC. Data from Chang et al. ${ }^{40}$ also support the hypothesis that HBV has greater impact on HCC development. In their study, incidence of HCC was $30.4 \%$ in coinfection with overt HBV replication compared to $13.9 \%$ in coinfection with occult HBV infection. ${ }^{40}$ Assuming HCV replication was relatively constant between these groups, it is

Table 3. Studies evaluating the frequency of HCC in coinfection versus monoinfection

\begin{tabular}{llll}
\hline Study & Prevalence in coinfection, $\%$ & $\begin{array}{l}\text { Prevalence in HBV } \\
\text { monoinfection, \% }\end{array}$ & $\begin{array}{l}\text { Prevalence in HCV } \\
\text { monoinfection, \% }\end{array}$ \\
\hline $\begin{array}{l}\text { Oh et al. }{ }^{37}, 2012 \\
\text { Chiaramonte et al. }{ }^{38}, 1999\end{array}$ & 21 & 5 & 3 \\
Hung et al. ${ }^{39}, 2005$ & 41 & 9 & 21 \\
Chang et al. ${ }^{40}, 2013$ & $\mathrm{HCV}+$ overt HBV: 30 & - & - \\
Yang et al. ${ }^{28}, 2016$ & $\mathrm{HCV}+$ occult HBV: 14 & - & - \\
Squadrito et al. ${ }^{32}, 2013$ & 17 & 7 & - \\
Benvegnu et al. ${ }^{41}, 1994$ & 35 & - & 9 \\
\hline
\end{tabular}

Abbreviations: HBV, hepatitis B virus; $\mathrm{HCC}$, hepatocellular carcinoma; HCV, hepatitis C virus. 
possible that the increased HBV replication in the overt HBV group led to the higher rate of HCC.

Shatori et al. ${ }^{37}$ also dispute an increased risk of HCC with coinfection. They suggested that viral replication was "mutually exclusive", and therefore, coinfection plays no role in HCC development. ${ }^{44}$ They reported a lower rate of HCC in coinfection at $2 \%$ compared to $10 \%$ in HBV monoinfection, $83 \%$ in $\mathrm{HCV}$ monoinfection and $5 \%$ in HBV/HCV negative patients. ${ }^{44}$ Because this study recruited only patients with $\mathrm{HCC}$ and then stratified them based on viral serology, these percentages likely reflect the prevalence of viral infection in this population. However, because coinfection is overall less common than HBV or HCV monoinfection, it is also relatively less frequent in patients with HCC. The design of this study did not allow for evaluation of the effect of coinfection compared to monoinfection on the development of HCC. Due to this fundamental flaw in study design, these data were also not included in Table 3.

\section{Management of coinfection}

The potential for worsening liver disease and HCC in coinfected patients emphasizes the importance of treatment. The general approach to treatment is to first identify the dominant virus, treat that virus as a monoinfection and then monitor for reactivation of the other virus. Fig. 2 provides an algorithmic approach to treatment in coinfection. Close monitoring for reactivation is required. ${ }^{5}$ The liver profile should be monitored regularly. If elevated transaminases are detected, HBV DNA should be monitored. ${ }^{42}$ There is no specific recommendation for frequency of monitoring during or after treatment.

HBV alone is typically treated with a nucleo(s)tide analog (such as lamivudine, entacavir, or tenofovir) and/or PegIFN. ${ }^{42}$ $\mathrm{HCV}$ monoinfection is treated primarily with DAAs, although in the past PegIFN plus ribavirin has been shown to be effective.
PegIFN-based therapy has some antiviral activity against both HBV and HCV. It is 35\% effective in HBV and $50-60 \%$ effective in HCV when combined with ribavirin. ${ }^{16}$ In contrast, DAAs are effective for HCV with sustained virological response exceeding $90 \%$, but have no effect on HBV. Unlike monoinfection, there are no clear treatment guidelines for HBV-HCV coinfection.

According to the European Association for the Study of the Liver, there is no difference in rate of HCV sustained virological response among coinfected and HCV monoinfected individuals. ${ }^{5}$ Supporting this are data from a prospective study comparing PegIFN and ribavirin treatment in coinfection and HCV monoinfection. ${ }^{46}$ The researchers found the sustained virological response rates to be $77.6 \%$ and $78.8 \%$, respectively. This study also showed that $25 \%$ of coinfected patients also had sustained seroclearance of hepatitis B surface antigen following treatment. Liu et al. ${ }^{47}$ demonstrated similar results with HCV sustained virological response among coinfected $(72.2 \%)$ versus HCV monoinfected $(77.3 \%)$ after PegIFN/ ribavirin therapy. Only $11.2 \%$ of the coinfected patients showed hepatitis B surface antigen clearance, which is significantly less than the prior study. ${ }^{47}$ Based on the described methods in each study, it is unclear why this difference was seen as the studies were of similar size, in the same region and time period, using the same inclusion criteria and treatment regimen. Overall, both of these studies confirmed that PegIFN/ ribavirin is equally effective for treatment of HCV and marginally effective for treatment of HBV in coinfected individuals.

A small multicenter study of nine hepatitis B e antigenpositive coinfected patients treated with PegIFN and ribavirin showed $78 \%$ of HCV SVR maintained over 3 year follow up. ${ }^{48}$ In a subgroup of five patients, lamivudine was added at week 12 of treatment. In the subgroup, $60 \%$ achieved hepatitis $\mathrm{B}$ e antigen seroconversion, whereas none of the PegIFN/ribavirin treated patients seroconverted. ${ }^{48}$ This study shows fair

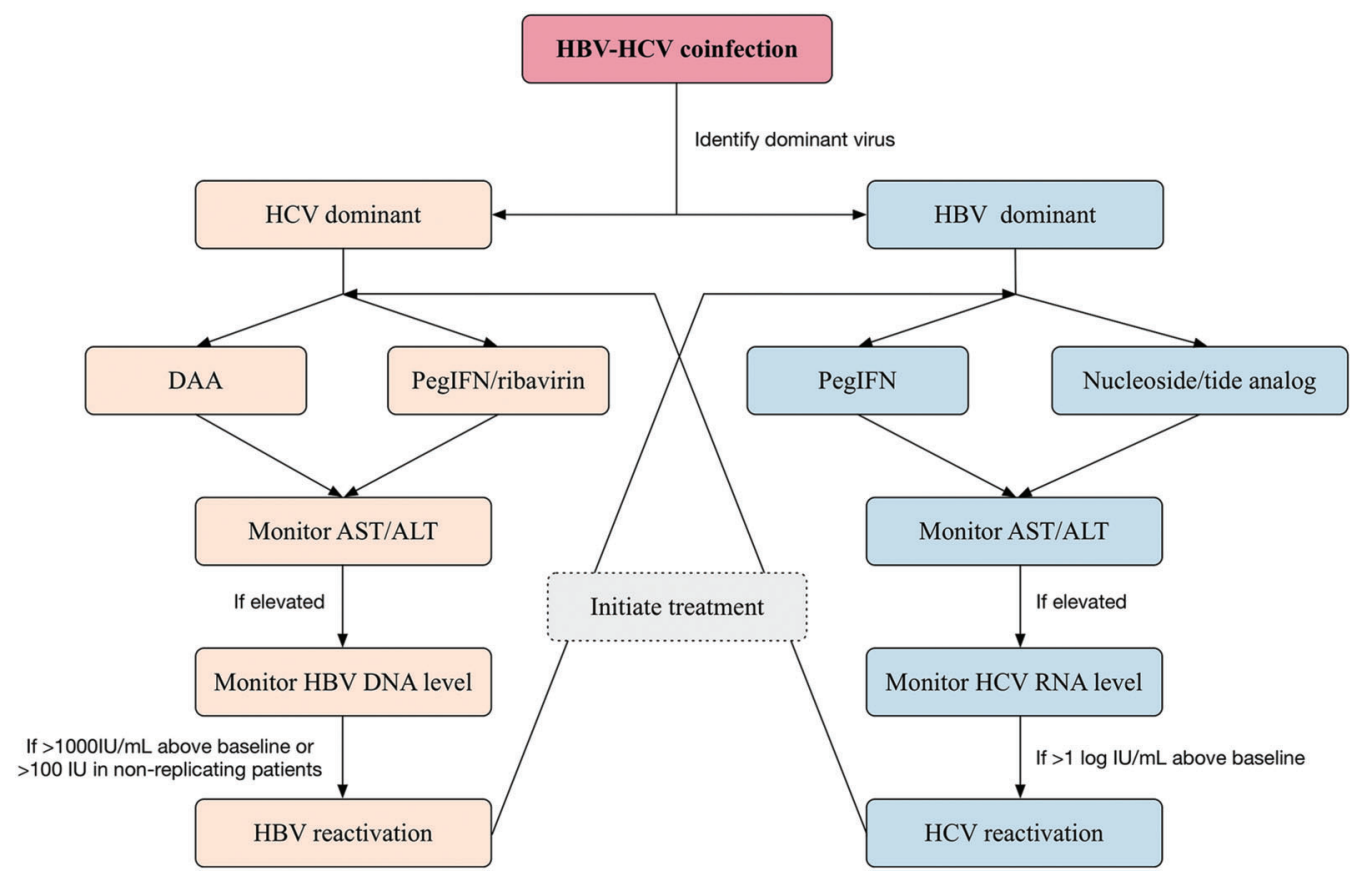

Fig. 2. An algorithm for the treatment of $\mathbf{H B V}-\mathbf{H C V}$ coinfection. Abbreviations: HBV, hepatitis B virus; HCV, hepatitis C virus. 
efficacy of the combination treatment regimen. However, the results may not be generalizable due to its very small sample size and inclusion of only hepatitis $B$ e antigen-positive individuals. The majority of coinfected patients were hepatitis B e antigen-negative. It is unclear how these regimens would perform in hepatitis $B$ e antigen-negative patients. A similar study evaluating interferon and lamivudine in eight coinfected individuals found the efficacy to be worse, with HCV SVR of $50 \%$ and suppression of HBV DNA in only $38 \%$, which was nonsustained. ${ }^{49}$ Like the above study, all participants were hepatitis $\mathrm{B}$ e antigen-positive. The treatment regimen was slightly different with interferon and lamivudine initiated concurrently in this study.

More recently, DAAs have also been explored in the treatment of coinfection. Calvaruso et al. ${ }^{50}$ showed good results with DAA treatment. This Italian retrospective study demonstrated an HCV sustained virological response of $94.2 \%$ among 45 coinfected individuals, although 6 individuals showed evidence of HBV reactivation requiring subsequent treatment with nucleoside analogs. ${ }^{50}$ This study included all HCV genotypes. However, it also included various DAA regimens based on genotype. Therefore, inferences are limited to DAAs as a class rather than specific medications or regimens. A similarly designed retrospective study done in the USA showed a significantly lower HCV sustained virological response of $76.7 \%$ following DAA treatment. ${ }^{51}$ Like the Italian study above, this also used a variety of DAAs. The difference in response to DAA treatment may be related to distribution of genotypes and treatment regimens, regional differences, or rates of cirrhosis among participants.

Anti-HCV treatment may improve outcomes in coinfection. All-cause mortality was decreased in PegIFN/ribavirin treated versus nontreated groups ( 7.4 vs. $19.6 \%)$, as was liver-related mortality (5.0 vs. $11.9 \%$ ). ${ }^{29}$ Treatment also decreased risk of developing HCC by $34 \% .{ }^{29}$ Within the data, the potential for $\mathrm{HBV}$ reactivation was not addressed. It is possible that the increased mortality associated with reactivation may negate some or all of the improved mortality seen in treatment groups.

HCV sustained virological response rates for PegIFN and DAA regimens from representative studies are listed in Table 4. The efficacy of PegIFN regimens is lower compared to DAAs for treatment of HCV in coinfection. However, their combined effect on dual infection is unimpressive when compared to risks of treatment. Overall, better treatment options are needed for this special population.

Due to the increased risk and complexity of management in coinfection, prevention is exceedingly important. Patients

Table 4. HBV reactivation rates in $\mathrm{HCV}$ dominant cases treated for $\mathrm{HCV}$

\begin{tabular}{|c|c|c|c|c|}
\hline Study & Treatment regimen & $\begin{array}{l}\text { Number of coinfected } \\
\text { participants }\end{array}$ & HCV SVR, \% & $\begin{array}{l}\text { Rate of } \\
\text { reactivation, \% }\end{array}$ \\
\hline Calvaruso et al. ${ }^{50}, 2018$ & $\begin{array}{l}\text { Mixed DAAs depending on } \\
\text { viral genotype }\end{array}$ & 45 & 94 & 2 \\
\hline Collins et al. ${ }^{54}, 2015$ & Sofosbuvir and simeprevir & 2 & 100 & 100 \\
\hline Sato et al. ${ }^{53}, 2017$ & $\begin{array}{l}\text { Sofosbuvir/ribavirin And } \\
\text { ombitasvir/paritap-revir/ritonavir }\end{array}$ & 2 & 100 & $100^{\wedge}$ \\
\hline Belperio et al. ${ }^{51}, 2017$ & Mixed DAAs & 30 & 77 & $27^{@}$ \\
\hline Gane et al. ${ }^{55}, 2016$ & Ledipasvir, sofosbuvir & 8 & 100 & 88 \\
\hline Wang et al. ${ }^{56}, 2016$ & DAAs & 134 & Unknown & 2 \\
\hline Kawagishi et al. ${ }^{57}, 2017$ & DAAs & 85 & Unknown & $7^{@}$ \\
\hline Ogawa et al. ${ }^{58}, 2018$ & DAAs & 63 & 94 & 6 \\
\hline Doi et al. ${ }^{59}, 2017$ & $\begin{array}{l}\text { Ledipasvir/sofosbuvir } \\
\text { Sofosbuvir/ribavirin }\end{array}$ & 147 & 100 & 3 \\
\hline Yeh et al. ${ }^{60}, 2017$ & DAAs & 64 & 97 & $6^{@}$ \\
\hline \multicolumn{4}{|c|}{ Average rate of reactivation with DAA therapy (Pooled sample) } & $8 \%(47 / 577)$ \\
\hline Yu et al. ${ }^{46}, 2013$ & PegIFN, ribavirin & 161 & 78 & $61 \wedge$ \\
\hline Portoff et al. ${ }^{61}, 2009$ & PegIFN, ribavirin & 11 & 91 & 82 \\
\hline Liu et al. ${ }^{47}, 2009$ & PegIFN, ribavirin & 77 & $72-77 *$ & 36 \\
\hline Yu et al. ${ }^{65}, 2009$ & PegIFN, ribavirin & 27 & 40 & 33 \\
\hline Liu et al. ${ }^{62}, 2009$ & PegIFN, ribavirin & 4 & 50 & 100 \\
\hline Chuang et al. ${ }^{63}, 2005$ & PegIFN, ribavirin & 25 & 40 & 44 \\
\hline Hung et al. ${ }^{39}, 2005$ & PegIFN, ribavirin & 18 & 56 & 44 \\
\hline Yeh et al. ${ }^{64}, 2015$ & PegIFN, ribavirin & 139 & $64-82 *$ & $27^{@}$ \\
\hline Wahle et al. ${ }^{66}, 2015$ & PegIFN only & 10 & 80 & 60 \\
\hline \multicolumn{4}{|c|}{ Average rate of reactivation with PegIFN \pm ribavirin therapy (Pooled sample) } & $49 \%(200 / 410)$ \\
\hline
\end{tabular}

*Varies based on genotype; ${ }^{\circledR}$ Signs of clinical reactivation noted; ^Reactivation nonsustained in some cases.

Abbreviations: DAA, direct-acting antiviral; HBV, hepatitis B virus; $\mathrm{HCV}$, hepatitis $\mathrm{C}$ virus; PegIFN, pegylated-interferon. 
with HCV monoinfection should be vaccinated against HBV to prevent superinfection. However, it is important to note that HBV immunization may be less effective in patients with chronic liver disease, such HCV infection. Roni et al. ${ }^{52}$ studied the efficacy of HBV vaccination in various populations and found that only $60 \%$ of cirrhotic patients responded to vaccination. Specifically, those with HCV infection had a $76 \%$ response rate, while $12 \%$ of patients were nonresponders, and another $12 \%$ were partial responders. ${ }^{52}$

\section{$\mathrm{HBV}$ reactivation as a consequence of treatment}

The approach to treating coinfection is more complex that treating each viral infection separately. Because of virallymediated inhibition by a dominant virus, its suppression can lead to reactivation of the nondominant virus. As mentioned above, most often HCV is dominant, suppressing HBV replication. As HCV is treated, its inhibitory effects on HBV replication can be released resulting in possible HBV reactivation. ${ }^{5}$ Some studies have suggested that with clearance of $\mathrm{HCV}$, there is increased replicative space for HBV. ${ }^{53}$ Changes in the host immune system following treatment and/or clearance of HCV may also contribute. ${ }^{53}$

$\mathrm{HBV}$ reactivation is defined as greater than 2 log increase in level of HBV DNA compared to baseline level or new appearance of HBV DNA at a level greater than $100 \mathrm{IU} / \mathrm{mL} .{ }^{53}$ The European Association for the Study of the Liver recommends that if $\mathrm{HBV}$ reactivation is detected following treatment of HCV, nucleo(s)tide analog treatment should be initiated. ${ }^{38}$ They also suggest that patients who are hepatitis B surface antigenpositive be treated prophylactically with nucleo(s)tide analog during and 12 weeks following DAA treatment. ${ }^{42}$ Others suggest that HBV treatment be held until there are clinical signs of flare, with rise in alanine aminotransferase. ${ }^{53}$ The latter strategy allows for any cases of transient HBV reactivation to clear spontaneously before exposing patients to the unpleasant side effects of more antiviral medications.

The rates of reactivation, seen in Table 4, are extremely variable across studies, ranging from $2.2-100 \%$. $50,54,33,39,47,51,53-66$ There appears to be agreement in some of the larger, more recent studies on DAAs in coinfection, ${ }^{57-60}$ with a trend toward lower rates of reactivation. Considering studies by treatment type, there is a higher pooled rate of reactivation with PegIFN-based regimens ( $48.8 \%$ vs. $8.1 \%)$. Even correcting for nonsustained HBV reactivation reported in some studies, the pooled rate of reactivation with PegIFN therapies was $35.6 \%$. This finding is somewhat counterintuitive given that the DAAs were designed to act solely on HCV, while the PegIFN regimens have some activity on both viruses. This may support immunomodulatory effects of DAAs in addition to intended DAA effects. It is difficult to compare the rate of reactivation across studies due to significant variability in study design, region, sample size, and inclusion criteria.

In contrast, a meta-analysis by Chen et al. ${ }^{67}$ determined the risk of reactivation to be similar between PegIFN versus DAA treatments $(14.5 \%$ vs. $12.2 \%) .{ }^{5}$ They also found that reactivation occurred earlier after treatment with DAAs and was more frequently clinically significant. ${ }^{67}$ Kawagishi et al. ${ }^{57}$ compared the two therapies in a single retrospective study where six patients $(7.1 \%)$ treated with a DAA had evidence of reactivation while no patients treated with PegIFN regimens reactivated. Although this seems like a stark contrast between the two therapies, the rate of reactivation for both therapies remained relatively low. This study did not report the HCV sustained virological response rate for each group individually. This would be important in weighing the risks and benefits of treatment. If DAAs had significantly higher sustained virological response compared to PegIFN, it may still be a better treatment option despite the increased risk of reactivation. To truly assess the difference in reactivation between the two treatment regimens, a head-to-head randomized control trial would be needed.

In many studies, a significant rise in HBV replication did not always correlate with clinical signs of reactivation. In a retrospective review of Veterans Affairs records, eight of thirty coinfected veterans $(26.6 \%)$ treated with DAAs showed HBV reactivated, as defined by increased in HBV DNA greater than $1000 \mathrm{IU} / \mathrm{mL}$ from pretreatment baseline. ${ }^{51}$ Furthermore, six of the eight veterans with HBV reactivation showed clinical signs of HBV flare, defined as peak in alanine aminotransferase level. ${ }^{51}$ A randomized trial of 139 coinfected patients found the same rate of reactivation at $26.6 \%$. However, only three patients $(2.2 \%)$ were reported to have symptoms of acute flare. ${ }^{64}$ A smaller study conducted in New Zealand had a higher reported rate of reactivation at $87.5 \%$ following DAA treatment. However, none of these individuals had clinical HBV flares. ${ }^{55}$ Unlike the studies mentioned above, many authors did not clearly differentiate clinical reactivation from serum elevations of HBV DNA.

Additionally, several studies reported an initial reactivation of HBV, which was nonsustained. For instance, Sato et al. ${ }^{53}$ reported a $100 \%$ reactivation rate in two patients treated with sofosbuvir and simeprevir; however, in both cases, reactivation resolved spontaneously. Similarly, Yu et al. ${ }^{46}$ reported a reactivation rate of $61.8 \%$ following treatment with PegIFN and ribavirin. However, reactivation was only sustained in $29.8 \%$ of cases. ${ }^{46}$ Although, the first study was a case series with only two patients, the latter was a fairly large, welldesigned, multicenter, prospective study with 5-year follow up period. Both author groups highlight the phenomenon of transient reactivation, which may have important implications for management. While the reactivation, meaning active HBV replication, occurred transiently after treatment in some cases, there is no evidence of complete HBV clearance. After HCV sustained virological response is achieved, there is a persistent potential for HBV reactivation at any time.

The long-term clinical significance of HBV reactivation that is either transient or clinically silent is unclear. More investigation into the impact of transient and or subclinical reactivation is warranted to gauge the need for monitoring in these special cases.

The presence of HBV in serum may also play a role in post-treatment reactivation. The rate of reactivation was significantly lower in occult HBV infection compared to overt infection ( $8.1 \%$ vs. $37.5 \%)$ in a study of 45 coinfected individuals treated with DAAs. ${ }^{50}$ This study showed an overall low rate of reactivation, at $2.2 \% .{ }^{50}$ Another large study of 848 patients showed that among a subgroup of hepatitis B surface antigen-negative/anti-hepatitis B core protein-positive patients, there were no cases of HBV reactivation after anti-HCV treatment. ${ }^{68}$ In contrast, five out of nine patients with overt HBV infection developed reactivation. ${ }^{68}$ While this study is impressive for its size, it is very difficult to interpret its data due to multiple treatment regimens including interferon-based, interferon-free, and some interferon-DAA combination regimens. The authors also categorized hepatitis B surface antigen-negative/antihepatitis B core protein-positive patients as "resolved HBV". 
However, without liver biopsy data, occult and resolved HBV cannot be distinguished.

\section{HCV reactivation}

There are some reports of HCV reactivation when HBV was treated first. However, this is seen much less commonly. HCV reactivation is defined as an increase in HCV RNA greater than $1 \mathrm{log} \mathrm{IU} / \mathrm{mL}$ above baseline level. ${ }^{3}$ Unlike HBV reactivation, it is usually clinically asymptomatic. HCV reactivation was seen in $12.5 \%$ of cases in a study of coinfected cirrhotic individuals treated with 18 months of nucleotide therapy. ${ }^{69}$ Among this cohort, HBV clearance was achieved in $96 \%$ of patients. ${ }^{65}$ This study was small with only 24 participants, and the authors did not clearly identify the dominant virus in each case prior to treatment. This may have some bearing on overall outcome as well as rate of HCV reactivation. Overall, since HCV is typically dominant and treated first, $\mathrm{HCV}$ reactivation is rarely seen.

\section{Conclusions}

Although HCV-HBV coinfection is somewhat rare, it has the potential to increase severity of liver disease and risk for complications, such as HCC. Treatment in coinfected patients is complex, due to interaction of the two viruses and potential for reactivation of either virus with antiviral therapy directed against only one of the viruses. It is important to be aware of potential for reactivation when treating HCV-HBV coinfection, especially as DAAs are becoming more widely available. Screening for HBV should be done prior to initiation of HCV therapy. Additionally, frequent monitoring for HBV DNA replication during treatment is required in coinfected individuals. Overall data in coinfected children is limited, as are the treatment options in the pediatric population. As such, the challenges in treated coinfection among children are slightly different than in adults.

\section{Acknowledgements}

This work was made possible by the Herman Lopata Chair in Hepatitis Research, and a grant from Alexion Corp. We are also grateful to Peg Atkinson Lee for assistance in the production of the original graphics included in this publication.

\section{Conflict of interest}

The authors have no conflict of interests related to this publication.

\section{Author contributions}

Drafting manuscript and development of figures (MGM), proposing concept for review and revising the manuscript with critical revisions (GYW).

\section{References}

[1] Peeling RW, Boeras DI, Marinucci F, Easterbrook P. The future of viral hepatitis testing: innovations in testing technologies and approaches. BMC Infect Dis 2017;17:699. doi: 10.1186/s12879-017-2775-0.

[2] Jamma S, Hussain G, Lau DT. Current concepts of HBV/HCV coinfection: coexistence, but not necessarily in harmony. Curr Hepat Rep 2010;9: 260-269. doi: 10.1007/s11901-010-0060-4.

[3] Pol S, Haour G, Fontaine H, Dorival C, Petrov-Sanchez V, Bourliere M, et al. The negative impact of $\mathrm{HBV} / \mathrm{HCV}$ coinfection on cirrhosis and its consequences. Aliment Pharmacol Ther 2017;46:1054-1060. doi: 10.1111/apt.14352.
[4] Konstantinou D, Deutsch M. The spectrum of HBV/HCV coinfection: epidemiology, clinical characteristics, viralinteractions and management. Ann Gastroenterol 2015;28:221-228.

[5] Sagnelli E, Sagnelli C, Macera M, Pisaturo M, Coppola N. An update on the treatment options for HBV/HCV coinfection. Expert Opin Pharmacother 2017;18:1691-1702. doi: 10.1080/14656566.2017.1398233.

[6] Senturk H, Tahan V, Canbakan B, Uraz S, Ulger Y, Ozaras R, et al. Chronic hepatitis $C$ responds poorly to combination therapy in chronic hepatis $B$ carriers. Neth J Med 2008;66:191-195.

[7] Holmes JA, Yu ML, Chung RT. Hepatitis B reactivation during or after direct acting antiviral therapy - implication for susceptible individuals. Expert Opin Drug Saf 2017;16:651-672. doi: 10.1080/14740338.2017.1325869.

[8] Marot A, Belaid A, Orlent H, Sersté T, Michielsen P, Colle I, et al. Characteristics of patients with hepatitis $B$ virus and hepatitis $C$ virus dual infection in a Western European country: Comparison with monoinfected patients. Clin Res Hepatol Gastroenterol 2017;41:656-663. doi: 10.1016/j.clinre.2017.05.003.

[9] Wieland SF, Asabe S, Engle RE, Purcell RH, Chisari FV. Limited hepatitis B virus replication space in the chronically hepatitis $C$ virus-infected liver. J Virol 2014;88:5184-5188. doi: 10.1128/JVI.03553-13.

[10] Yang D, Zuo C, Wang X, Meng X, Xue B, Liu N, et al. Complete replication of hepatitis $B$ virus and hepatitis $C$ virus in a newly developed hepatoma cell line. Proc Natl Acad Sci U S A 2014;111:E1264-E1273. doi: 10.1073/pnas. 1320071111.

[11] Bellecave P, Gouttenoire J, Gajer M, Brass V, Koutsoudakis G, Blum HE, et al. Hepatitis $B$ and $C$ virus coinfection: a novel model system reveals the absence of direct viral interference. Hepatology 2009;50:46-55. doi: 10.1002/hep.22951.

[12] Pan Y, Wei W, Kang L, Wang Z, Fang J, Zhu Y, et al. NS5A protein of HCV enhances HBV replication and resistance to interferon response. Biochem Biophys Res Commun 2007;359:70-75. doi: 10.1016/j.bbrc.2007.05.052.

[13] Eyre NS, Phillips RJ, Bowden S, Yip E, Dewar B, Locarnini SA, et al. Hepatitis B virus and hepatitis $C$ virus interaction in Huh-7 cells. J Hepatol 2009;51: 446-457. doi: 10.1016/j.jhep.2009.04.025.

[14] Schüttler CG, Fiedler N, Schmidt K, Repp R, Gerlich WH, Schaefer S. Suppression of hepatitis $B$ virus enhancer 1 and 2 by hepatitis $C$ virus core protein. J Hepatol 2002;37:855-862. doi: 10.1016/S0168-8278(02)00296-9.

[15] Gordon SC, Sherman KE. Treatment of HBV/HCV coinfection: releasing the enemy within. Gastroenterology 2009;136:393-396. doi: 10.1053/j.gastro. 2008.12.017.

[16] Crockett SD, Keeffe EB. Natural history and treatment of hepatitis B virus and hepatitis C virus coinfection. Ann Clin Microbiol Antimicrob 2005;4:13. doi: 10.1186/1476-0711-4-13.

[17] Shih CM, Chen CM, Chen SY, Lee YH. Modulation of the trans-suppression activity of hepatitis C virus core protein by phosphorylation. J Virol 1995;69: $1160-1171$.

[18] Chen SY, Kao CF, Chen CM, Shih CM, Hsu MJ, Chao CH, et al. Mechanisms for inhibition of hepatitis $B$ virus gene expression and replication by hepatitis C virus core protein. J Biol Chem 2003;278:591-607. doi: 10. $1074 / j b c . M 204241200$

[19] Caccamo G, Saffioti F, Raimondo G. Hepatitis B virus and hepatitis C virus dual infection. World J Gastroenterol 2014;20:14559-14567. doi: 10. 3748/wjg.v20.i40.14559.

[20] Cardoso C, Alves AL, Augusto F, Freire R, Quintana C, Gonçalves M, et al. Occult hepatitis B infection in Portuguese patients with chronic hepatitis $C$ liver disease: prevalence and clinical significance. Eur J Gastroenterol Hepatol 2013;25:142-146. doi: 10.1097/MEG.0b013e328359fe54.

[21] Kannangai R, Vivekanandan P, Netski D, Mehta S, Kirk GD, Thomas DL, et al. Liver enzyme flares and occult hepatitis $B$ in persons with chronic hepatitis C infection. J Clin Virol 2007;39:101-105. doi: 10.1016/j.jcv.2007.03.006.

[22] Wiegand SB, Jaroszewicz J, Potthoff A, Höner Zu Siederdissen C, Maasoumy $B$, Deterding K, et al. Dominance of hepatitis $C$ virus (HCV) is associated with lower quantitative hepatitis $B$ surface antigen and higher serum interferon$\gamma$-induced protein 10 levels in HBV/HCV-coinfected patients. Clin Microbiol Infect 2015;21:710.e1-710.e9. doi: 10.1016/j.cmi.2015.03.003.

[23] Raimondo G, Brunetto MR, Pontisso P, Smedile A, Maina AM, Saitta C, et al. Longitudinal evaluation reveals a complex spectrum of virological profiles in hepatitis B virus/hepatitis C virus-coinfected patients. Hepatology 2006;43: 100-107. doi: 10.1002/hep.20944.

[24] Rodríguez-Iñigo E, Bartolomé ], Ortiz-Movilla N, Platero C, López-Alcorocho $\mathrm{JM}$, Pardo $\mathrm{M}$, et al. Hepatitis $\mathrm{C}$ virus (HCV) and hepatitis B virus (HBV) can coinfect the same hepatocyte in the liver of patients with chronic HCV and occult HBV infection. J Virol 2005;79:15578-15581. doi: 10.1128/JVI.79. 24.15578-15581.2005.

[25] Xiong $H$, Rong X, Wang M, Xu R, Huang K, Liao Q, et al. HBV/HCV co-infection is associated with a high level of HCV spontaneous clearance among drug users and blood donors in China. J Viral Hepat 2017;24:312-319. doi: 10. $1111 /$ jvh.12644.

[26] Sheen IS, Liaw YF, Chu CM, Pao CC. Role of hepatitis C virus infection in spontaneous hepatitis B surface antigen clearance during chronic hepatitis B virus infection. J Infect Dis 1992;165:831-834 doi: 10.1093/infdis/165.5.831. 
[27] Yan LB, Rao HY, Ma Y], Bai L, Chen EQ, Du LY, et al. Hepatitis B virus infection in Chinese patients with hepatitis $C$ virus infection: prevalence, clinical characteristics, viral interactions and host genotypes: a nationwide cross-sectional study. BMJ Open 2016;6:e012016. doi: 10.1136/bmjopen-2016-012016.

[28] Yang WT, Wu LW, Tseng TC, Chen CL, Yang HC, Su TH, et al. Hepatitis B surface antigen loss and hepatocellular carcinoma development in patients with dual hepatitis B and C infection. Medicine (Baltimore) 2016;95:e2995. doi: 10.1097/MD.0000000000002995.

[29] Liu CJ, Chu YT, Shau WY, Kuo RN, Chen PJ, Lai MS. Treatment of patients with dual hepatitis $C$ and $B$ by peginterferon $\alpha$ and ribavirin reduced risk of hepatocellular carcinoma and mortality. Gut 2014;63:506-514. doi: 10. 1136/gutjnl-2012-304370.

[30] Lee CC, Li IJ, Chen YC, Cheng JW, Wu HH, Weng CH, et al. Comparable tenyear outcome in hemodialysis patients with hepatitis $C$ virus and hepatitis $B$ virus coinfection and single hepatitis B virus infection. Blood Purif 2011;32: 89-95. doi: 10.1159/000324196.

[31] Gaeta GB, Stornaiuolo G, Precone DF, Lobello S, Chiaramonte M, Stroffolini T, et al. Epidemiological and clinical burden of chronic hepatitis $B$ virus/hepatitis C virus infection. A multicenter Italian study. J Hepatol 2003;39:1036-1041. doi: 10.1016/S0168-8278(03)00470-7.

[32] Squadrito G, Cacciola I, Alibrandi A, Pollicino T, Raimondo G. Impact of occult hepatitis $B$ virus infection on the outcome of chronic hepatitis $C$. J Hepatol 2013;59:696-700. doi: 10.1016/j.jhep.2013.05.043.

[33] Zarski JP, Bohn B, Bastie A, Pawlotsky JM, Baud M, Bost-Bezeaux F, et al. Characteristics of patients with dual infection by hepatitis $B$ and $C$ viruses. J Hepatol 1998;28:27-33. doi: 10.1016/S0168-8278(98)80198-0.

[34] Pokorska-Śpiewak M, Kowalik-Mikołajewska B, Aniszewska M, WalewskaZielecka B, Marczyńska M. The influence of hepatitis $B$ and $C$ virus coinfection on liver histopathology in children. Eur J Pediatr 2015;174:345-353. doi: 10. 1007/s00431-014-2402-7.

[35] Indolfi G, Hierro L, Dezsofi A, Jahnel J, Debray D, Hadzic N, et al. Treatment of chronic hepatitis $C$ virus infection in children: a position paper by the hepatology committee of european society of paediatric gastroenterology, hepatology and nutrition. J Pediatr Gastroenterol Nutr 2018;66:505-515. doi: 10.1097/MPG.0000000000001872.

[36] Komatsu $H$, Inui $A$, Fujisawa T. Pediatric hepatitis B treatment. Ann Trans Med 2017;5:37. doi: 10.21037/atm.2016.11.52.

[37] Oh JK, Shin HR, Lim MK, Cho H, Kim DI, Jee Y, et al. Multiplicative synergistic risk of hepatocellular carcinoma development among hepatitis $\mathrm{B}$ and $\mathrm{C}$ coinfected subjects in HBV endemic area: a community-based cohort study. BMC Cancer 2012;12:452. doi: 10.1186/1471-2407-12-452.

[38] Chiaramonte M, Stroffolini T, Vian A, Stazi MA, Floreani A, Lorenzoni U, et al. Rate of incidence of hepatocellular carcinoma in patients with compensated viral cirrhosis. Cancer 1999;85:2132-2137. doi: 10.1002/(SICI)1097-0142 (19990515)85:10<2132: :AID-CNCR6>3.0.CO;2-H.

[39] Hung $\mathrm{CH}$, Lee $\mathrm{CM}$, Lu SN, Wang JH, Tung $\mathrm{HD}$, Chen $\mathrm{CH}$, et al. Combination therapy with interferon-alpha and ribavirin in patients with dual hepatitis $\mathrm{B}$ and hepatitis C virus infection. J Gastroenterol Hepatol 2005;20:727-732. doi: 10.1111/j.1440-1746.2005.03791.x.

[40] Chang ML, Lin YJ, Chang CJ, Yeh C, Chen TC, Yeh TS, et al. Occult and overt HBV co-infections independently predict postoperative prognosis in HCVassociated hepatocellular carcinoma. PLoS One 2013;8:e64891. doi: 10. 1371/journal.pone.0064891.

[41] Benvegnù L, Fattovich G, Noventa F, Tremolada F, Chemello L, Cecchetto A, et al. Concurrent hepatitis $B$ and $C$ virus infection and risk of hepatocellular carcinoma in cirrhosis. A prospective study. Cancer 1994;74:2442-2448. doi: 10. 1002/1097-0142(19941101)74:9<2442::AID-CNCR2820740909>3.0.CO;2-\#.

[42] Sulaiman HA. The development of hepatocellular carcinoma from liver cirrhosis during a follow-up study. Gastroenterol Jpn 1989;24:567-572.

[43] Kuper HE, Tzonou A, Kaklamani E, Hadziyannis S, Tasopoulos N, Lagiou P, et al. Hepatitis $B$ and $C$ viruses in the etiology of hepatocellular carcinoma; a study in Greece using third-generation assays. Cancer Causes Control 2000; 11:171-175. doi: 10.1023/A:1008951901148.

[44] Shiratori Y, Shiina S, Zhang PY, Ohno E, Okudaira T, Payawal DA, et al. Does dual infection by hepatitis $B$ and $C$ viruses play an important role in the pathogenesis of hepatocellular carcinoma in Japan? Cancer 1997;80: 2060-2067. doi: 10.1002/(SICI)1097-0142(19971201)80:11<2060: AID-CNCR4>3.0.CO;2-0.

[45] EASL 2017 Clinical Practice Guidelines on the management of hepatitis B. virus infection. J Hepatol 2017;67:370-398. doi: 10.1016/j.jhep.2017.03.021.

[46] Yu ML, Lee CM, Chen CL, Chuang WL, Lu SN, Liu CH, et al. Sustained hepatitis $C$ virus clearance and increased hepatitis $B$ surface antigen seroclearance in patients with dual chronic hepatitis $\mathrm{C}$ and $\mathrm{B}$ during posttreatment follow-up. Hepatology 2013;57:2135-2142. doi: 10.1002/hep.26266.

[47] Liu CJ, Chuang WL, Lee CM, Yu ML, Lu SN, Wu SS, et al. Peginterferon alfa-2a plus ribavirin for the treatment of dual chronic infection with hepatitis $B$ and $C$ viruses. Gastroenterology 2009;136:496-504.e3. doi: 10.1053/j.gastro. 2008.10.049.

[48] Yeh ML, Hsieh MY, Huang CI, Huang CF, Hsieh MH, Huang JF, et al. Long-term efficacy of Peg-Interferon/Ribavirin with and without Lamivudine therapy for
HBeAg-positive hepatitis B and C dual infection. J Gastroenterol Hepatol 2016;31:835-841. doi: 10.1111/jgh.13203.

[49] Marrone A, Zampino R, D'Onofrio M, Ricciotti R, Ruggiero G, Utili R. Combined interferon plus lamivudine treatment in young patients with dual HBV (HBeAg positive) and HCV chronic infection. J Hepatol 2004;41:1064-1065. doi: 10.1016/j.jhep.2004.07.009.

[50] Calvaruso V, Ferraro D, Licata A, Bavetta MG, Petta S, Bronte F, et al. HBV reactivation in patients with $\mathrm{HCV} / \mathrm{HBV}$ cirrhosis on treatment with directacting antivirals. J Viral Hepat 2018;25:72-79. doi: 10.1111/jvh.12754.

[51] Belperio PS, Shahoumian TA, Mole LA, Backus LI. Evaluation of hepatitis B reactivation among 62,920 veterans treated with oral hepatitis $C$ antivirals. Hepatology 2017;66:27-36. doi: 10.1002/hep.29135.

[52] Roni DA, Pathapati RM, Kumar AS, Nihal L, Sridhar K, Tumkur Rajashekar S. Safety and efficacy of hepatitis B vaccination in cirrhosis of liver. Adv Virol 2013;2013:196704. doi: 10.1155/2013/196704.

[53] Sato K, Kobayashi T, Yamazaki Y, Takakusagi S, Horiguchi N, Kakizaki S, et al. Spontaneous remission of hepatitis B virus reactivation during direct-acting antiviral agent-based therapy for chronic hepatitis C. Hepatol Res 2017;47: 1346-1353. doi: 10.1111/hepr.12905.

[54] Collins JM, Raphael KL, Terry C, Cartwright EJ, Pillai A, Anania FA, et al. Hepatitis $B$ virus reactivation during successful treatment of hepatitis $C$ virus with sofosbuvir and simeprevir. Clin Infect Dis 2015;61:1304-1306. doi: $10.1093 /$ cid/civ474.

[55] Gane EJ, Hyland RH, An D, Svarovskaia ES, Brainard D, McHutchison JG. Ledipasvir and sofosbuvir for HCV infection in patients coinfected with HBV. Antivir Ther 2016;21:605-609. doi: 10.3851/IMP3066.

[56] Wang C, Ji D, Chen J, Shao Q, Li B, Liu J, et al. Hepatitis due to reactivation of hepatitis $B$ virus in endemic areas among patients with hepatitis $C$ treated with direct-acting antiviral agents. Clin Gastroenterol Hepatol 2017;15:132136. doi: 10.1016/j.cgh.2016.06.023.

[57] Kawagishi N, Suda G, Onozawa M, Kimura M, Maehara O, Ohara M, et al. Comparing the risk of hepatitis $B$ virus reactivation between direct-acting antiviral therapies and interferon-based therapies for hepatitis C. J Viral Hepat 2017;24:1098-1106. doi: 10.1111/jvh.12737.

[58] Ogawa E, Furusyo N, Murata M, Toyoda K, Hayashi T, Ura K. Potential risk of HBV reactivation in patients with resolved HBV infection undergoing direct-acting antiviral treatment for HCV. Liver Int 2018;38:76-83. doi: 10.1111/liv.13496.

[59] Doi A, Sakamori R, Tahata Y, Urabe A, Morishita N, Yamada R, et al. Frequency of, and factors associated with, hepatitis $B$ virus reactivation in hepatitis $C$ patients treated with all-oral direct-acting antivirals: Analysis of a Japanese prospective cohort. Hepatol Res 2017;47:1438-1444. doi: 10. 1111/hepr.12919.

[60] Yeh ML, Huang CF, Hsieh MH, Ko YM, Chen KY, Liu TW, et al. Reactivation of hepatitis $B$ in patients of chronic hepatitis $C$ with hepatitis $B$ virus infection treated with direct acting antivirals. J Gastroenterol Hepatol 2017;32: 1754-1762. doi: 10.1111/jgh.13771.

[61] Potthoff A, Berg $T$, Wedemeyer $H$. Late hepatitis $B$ virus relapse in patients co-infected with hepatitis $B$ virus and hepatitis $C$ virus after antiviral treatment with pegylated interferon-a2b and ribavirin. Scand J Gastroenterol 2009;44:1487-1490. doi: 10.3109/00365520903329585.

[62] Liu CJ, Chen PJ, Lai MY, Kao JH, Jeng YM, Chen DS. Ribavirin and interferon is effective for hepatitis $C$ virus clearance in hepatitis $B$ and $C$ dually infected patients. Hepatology 2003;37:568-576. doi: 10.1053/jhep.2003.50096.

[63] Chuang WL, Dai CY, Chang WY, Lee LP, Lin ZY, Chen SC, et al. Viral interaction and responses in chronic hepatitis $C$ and $B$ coinfected patients with interferonalpha plus ribavirin combination therapy. Antivir Ther 2005;10:125-133.

[64] Yeh ML, Hsieh MY, Huang CI, Huang CF, Hsieh MH, Liang PC, et al. Personalized therapy of chronic hepatitis $\mathrm{C}$ and $\mathrm{B}$ dually infected patients with pegylated interferon plus ribavirin: a randomized study. Medicine (Baltimore) 2015;94:e1837. doi: 10.1097/MD.0000000000001837.

[65] Yu JW, Sun LJ, Zhao YH, Kang P, Gao J, Li SC. Analysis of the efficacy of treatment with peginterferon alpha-2a and ribavirin in patients coinfected with hepatitis B virus and hepatitis C virus. Liver Int 2009;29:1485-1493. doi: $10.1111 / \mathrm{j} .1478-3231.2009 .02080 . x$.

[66] Wahle RC, Perez RM, Pereira PF, Oliveira EM, Emori CT, Uehara SN, et al. Hepatitis $B$ virus reactivation after treatment for hepatitis $C$ in hemodialysis patients with HBV/HCV coinfection. Braz J Infect Dis 2015;19:533-537. doi: 10.1016/j.bjid.2015.04.003.

[67] Chen G, Wang C, Chen J, Ji D, Wang Y, Wu V, et al. Hepatitis B reactivation in hepatitis $B$ and $C$ coinfected patients treated with antiviral agents: A systematic review and meta-analysis. Hepatology 2017;66:13-26. doi: 10. 1002/hep.29109.

[68] Mücke VT, Mücke MM, Peiffer KH, Weiler N, Welzel TM, Sarrazin C, et al. No evidence of hepatitis $B$ virus reactivation in patients with resolved infection treated with direct-acting antivirals for hepatitis $\mathrm{C}$ in a large real-world cohort. Aliment Pharmacol Ther 2017;46:432-439. doi: 10.1111/apt.14177.

[69] Coppola N, Marrone A, Pisaturo M, Starace M, Signoriello G, Gentile I, et al. Role of interleukin 28-B in the spontaneous and treatment-related clearance of $\mathrm{HCV}$ infection in patients with chronic $\mathrm{HBV} / \mathrm{HCV}$ dual infection. Eur J Clin Microbiol Infect Dis 2014;33:559-567. doi: 10.1007/s10096-013-1985-7. 